\title{
Low Frequency of Human Papillomavirus and Epstein-Barr Virus DNA in Ameloblastoma of Thai Patients
}

\author{
Dusit Bumalee ${ }^{1}$, Puangwan Lapthanasupkul ${ }^{2}$, Eakapong Tamboon ${ }^{3}$, Anchisa Aittiwarapoj ${ }^{4}$, Boworn Klongnoi $^{5}$, \\ Nakarin Kitkumthorn 6
}

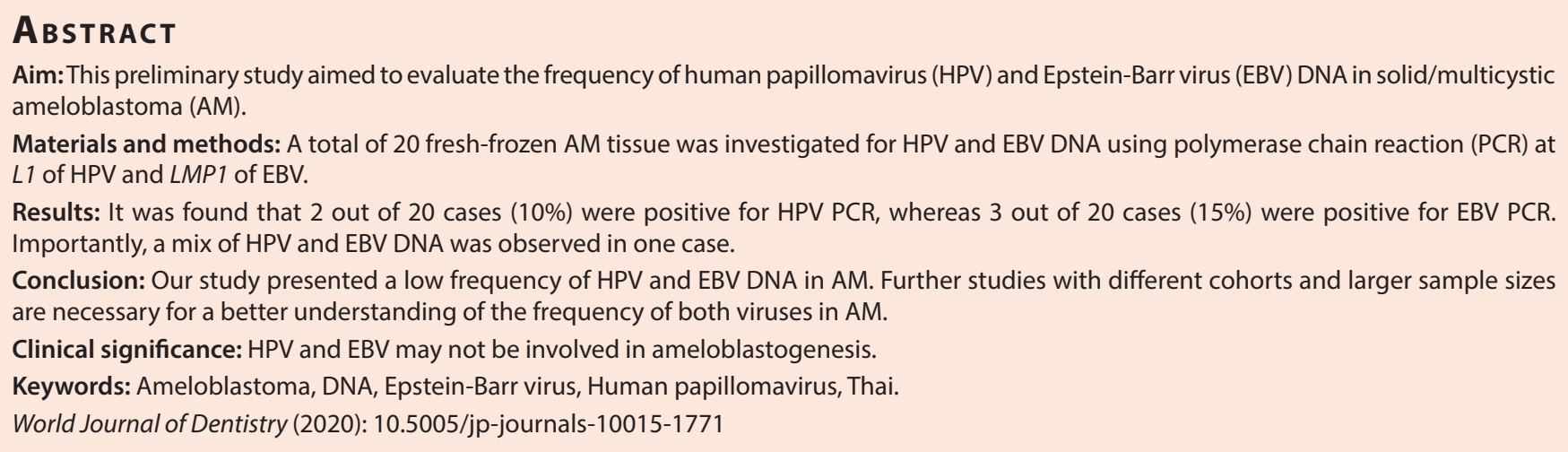

\section{INTRODUCTION}

Ameloblastoma (AM) is a benign neoplasm derived from residual epithelial components of tooth development and generally present in the jawbone.The majority of AM occurs in patients between 20 and 40 years of age, although they can occur at any age. Ameloblastoma was observed in 1\% of maxillofacial tumors and approximately $35 \%$ of odontogenic tumors in Thailand AM-solid/ multicystic type. ${ }^{1-3}$ This tumor is often asymptomatic, slow-growing but shows locally aggressive behavior and has high recurrence potential among odontogenic tumors.The mechanisms involved in the pathogenesis of AM have not been completely elucidated. Factors such as trauma, tooth eruption, and viral infection have been reported with AM etiopathogenesis. ${ }^{3-5}$

To date, several studies reported an association between the presences of viral DNA in many cancers. Both human papillomavirus (HPV) and Epstein-Barr virus (EBV) are known as oncogenic viruses. ${ }^{6,7}$ Human papillomavirus infection is the most common sexually transmitted infection and about $9-13 \%$ of the world's population is already infected. ${ }^{8}$ High-risk HPV (hrHPV) is an established cause of various human neoplasms including cervical, vulvar, sinonasal, oral, and penile cancers..$^{8-11}$ In addition, EBV is the first human tumor virus that is observed in more than $90 \%$ of the world's adult population. ${ }^{6}$ Epstein-Barr virus can contact and cause infectious mononucleosis during childhood. In addition, EBV infection could be linked to several other types of human malignancies, particularly nasopharyngeal cancer (NPC), gastric cancer (GC), Burkitt's lymphoma, some Hodgkin's lymphoma, and B-cell lymphoma., ${ }^{6,12}$

Epstein-Barr virus and HPV implicate to cellular immortalization and oncogenesis. Their genetic materials can produce viral oncoproteins that inhibit tumor suppressor gene and/or integrate viral DNA to the human genome. ${ }^{13,14}$ Considering the ameloblastoma pathogenesis, the relationship with HPV and EBV
1,2,4 Department of Oral and Maxillofacial Pathology, Faculty of
Dentistry, Mahidol University, Bangkok, Thailand
${ }^{3,6}$ Department of Oral Biology, Faculty of Dentistry, Mahidol University,
Bangkok, Thailand
${ }^{5}$ Department of Oral and Maxillofacial Surgery, Faculty of Dentistry, Mepartment of Oral and Maxillofacial

Corresponding Author: Nakarin Kitkumthorn, Department of Oral Biology, Faculty of Dentistry, Mahidol University, Bangkok, Thailand, Phone: +(66)2200-7849, e-mail: Nakarinkit@gmail.com

How to cite this article: Bumalee D, Lapthanasupkul P, Tamboon E, et al. Low Frequency of Human Papillomavirus and Epstein-Barr Virus DNA in Ameloblastoma of Thai Patients. World J Dent 2020;11(6): 446-450.

Source of support: Faculty of Dentistry, Mahidol University Conflict of interest: None

is needed to be substantiated. In this study, we aimed to evaluate the frequency of HPV and EBV DNA in solid/multicystic AM which could contribute to the knowledge concerning viral-associated AM patients in Thailand.

\section{Materials and Methods \\ Ethical Statement and Sample Recruitment}

Ethical consideration of this cross-sectional study was reviewed and approved by the Institutional Review Board of Faculty of the Dentistry/Faculty of Pharmacy, Mahidol University, Bangkok, Thailand (Approval number: 2018/005.1101). An informed consent was obtained from all patients before the collection of specimens. Data were analyzed anonymously. A total of 20 fresh-frozen tissue samples were obtained from the Department of Oral and Maxillofacial Surgery, Faculty of Dentistry, Mahidol University, 
Table 1: Clinicopathological features of ameloblastoma patients and results of EBV and HPV PCR

\begin{tabular}{|c|c|c|c|c|c|c|}
\hline Code & Sex & Age & Location & $\begin{array}{l}\text { Histological } \\
\text { subtype }\end{array}$ & $E B V P C R$ & $H P V P C R$ \\
\hline AM1 & $\mathrm{F}$ & 30 & Mandible & Plexiform & Positive & Positive \\
\hline AM2 & M & 63 & Mandible & Plexiform & Negative & Negative \\
\hline AM3 & $F$ & 47 & Mandible & Plexiform & Negative & Negative \\
\hline AM4 & $M$ & 11 & Mandible & Plexiform & Positive & Negative \\
\hline AM5 & $\mathrm{F}$ & 60 & Mandible & Follicular & Negative & Negative \\
\hline AM6 & M & 66 & Mandible & Plexiform & Positive & Negative \\
\hline AM7 & M & 23 & Mandible & Follicular & Negative & Positive \\
\hline AM8 & M & 51 & Mandible & Follicular & Negative & Negative \\
\hline AM9 & $\mathrm{F}$ & 30 & Mandible & Plexiform & Negative & Negative \\
\hline AM10 & $M$ & 37 & Mandible & Plexiform & Negative & Negative \\
\hline AM11 & $M$ & 59 & Mandible & Follicular & Negative & Negative \\
\hline AM12 & M & 44 & Maxilla & Follicular & Negative & Negative \\
\hline AM13 & $\mathrm{F}$ & 24 & Mandible & Plexiform & Negative & Negative \\
\hline AM14 & $F$ & 25 & Maxilla & Follicular & Negative & Negative \\
\hline AM15 & M & 54 & Mandible & Plexiform & Negative & Negative \\
\hline AM16 & $\mathrm{F}$ & 54 & Maxilla & Plexiform & Negative & Negative \\
\hline AM17 & $M$ & 73 & Mandible & Follicular & Negative & Negative \\
\hline AM18 & $\mathrm{F}$ & 8 & Mandible & Follicular & Negative & Negative \\
\hline AM19 & M & 66 & Maxilla & Plexiform & Negative & Negative \\
\hline AM20 & M & 50 & Mandible & Plexiform & Negative & Negative \\
\hline
\end{tabular}

F, female; $M$, male

during January 1,2018 , to December 31, 2019. These AM patients were Thai- 12 males and 8 females with a median age of 48.5 years (range $8-73$ years). Most cases were located in the mandible while only four cases were located in the maxilla. All cases were histologically confirmed as solid multicystic AM 8 follicular and 12 plexiform histological subtypes by two oral pathologists based on current World Health Organization (WHO) guidelines. ${ }^{15}$ Clinical and pathological data such as age, sex, anatomic location of the lesions, and histological subtypes are summarized in Table 1.

\section{DNA Isolation}

Fresh-frozen tissues were lysed at $50^{\circ} \mathrm{C}$ overnight with a lysis buffer $(0.75 \mathrm{~mol} / \mathrm{L} \mathrm{NaCl}, 0.024 \mathrm{~mol} / \mathrm{L}$ EDTA, $\mathrm{pH} 8.0$ ) that was mixed with $10 \%$ sodium dodecyl sulfate (SDS) and $20 \mathrm{mg} / \mathrm{mL}$ proteinase $\mathrm{K}$ (Sigma-Aldrich, St. Louis, MO, USA). Next, the DNA purification was done using a standard phenol-chloroform extraction protocol. ${ }^{16}$ Thereafter, the purified DNA was air-dried, eluted with distilled water, and stored below $-20^{\circ} \mathrm{C}$ for subsequent use. The DNA concentration was measured using a NanoDrop 2000 spectrophotometer (ND-2000 Spectrophotometer, NanoDrop Technologies, Wilmington, DE, USA). The optical density 260/280 ratio was greater than 1.8 , which is acceptable for DNA purity and PCR.

\section{Detection of EBV and HPV DNA by Polymerase Chain Reaction}

Polymerase chain reaction (PCR) was performed using the primers, displayed sequences, and conditions as shown in Table 2. Glyceraldehyde 3-phosphate dehydrogenase (GAPDH) served as the internal control to test the quality of DNA. The $L 1 \mathrm{HPV}$ primer $(\mathrm{GP} 5+/ \mathrm{GP} 6)^{17}$ that encodes major capsid protein of HPV was tested
Table 2: Oligonucleotide primer sequences and conditions for PCR analyses

\begin{tabular}{|c|c|c|c|c|}
\hline Detection & Primer & Sequence $5^{\prime}-3^{\prime}$ & $\begin{array}{l}\text { Amplicon } \\
\text { size (bp) }\end{array}$ & $\begin{array}{l}\text { Annealing } \\
\text { temperature } \\
\left({ }^{\circ} \mathrm{C}\right)\end{array}$ \\
\hline \multirow{2}{*}{$\begin{array}{l}\text { Internal } \\
\text { control } \\
(G A P D H)\end{array}$} & $\begin{array}{l}\text { GAPDH } \\
\text { forward }\end{array}$ & $\begin{array}{l}\text { CAGCCG- } \\
\text { CATCTTCTTTTG }\end{array}$ & 150 & 60 \\
\hline & $\begin{array}{l}\text { GAPDH } \\
\text { reverse }\end{array}$ & $\begin{array}{l}\text { CAACAATATC- } \\
\text { CACTTTAC }\end{array}$ & & \\
\hline \multirow[t]{2}{*}{ EBV DNA } & $\begin{array}{l}\angle M P 1 \\
\text { forward }\end{array}$ & $\begin{array}{l}\text { CCAGACAGC- } \\
\text { CAACAATTG }\end{array}$ & 129 & 64 \\
\hline & $\begin{array}{l}\angle M P 1 \\
\text { reverse }\end{array}$ & $\begin{array}{l}\text { GGTAGAAGAC- } \\
\text { CСCCTAC }\end{array}$ & & \\
\hline \multirow[t]{2}{*}{ HPV DNA } & GP5+ & $\begin{array}{l}\text { TTTGTTACT- } \\
\text { GTGGTAGATAC- } \\
\text { TAC }\end{array}$ & 150 & 56 \\
\hline & GP6+ & $\begin{array}{l}\text { CTTATAC- } \\
\text { TAAATGT- } \\
\text { CAAATAAAAAG }\end{array}$ & & \\
\hline
\end{tabular}

to detect HPV DNA. The LMP-1 EBV primer ${ }^{18}$ that encodes EBV latent membrane protein was tested to detect EBV DNA.

The PCR mixtures of all reactions contained $1 \times$ PCR buffer, 200 mM dNTPs, $0.2 \mathrm{mM}$ primers, $0.5 \mathrm{U}$ Taq DNA polymerase (Qiagen, San Diego, CA, USA), and $50 \mathrm{ng}$ of template DNA. DNA from the B958 and HeLa cell lines was used as the positive controls of EBV PCR and HPV $P C R$, respectively. Distilled water was used as the negative control in every $P C R$ reaction. Following amplification, the $P C R$ products were separated by gel electrophoresis using a $2 \%$ agarose gel in 
TBE buffer and then stained with SYBR Green nucleic acid gel stain (Gelstar, Lonza, Allendale, NJ, USA). Furthermore, the PCR product being positive for HPV DNA was investigated for HPV typing by Sanger sequencing. The sequencing data were then identified for the HPV genotype by nucleotide blast using https://blast.ncbi. nlm.nih.gov/Blast.cgi. Due to the limited positive cases, descriptive statistics were used for characterization of the sample.

\section{Results}

As shown in Table 1, the frequency of EBV and HPV was 3/20 (15\%) and $2 / 20(10 \%)$, respectively. From the histopathological feature, koilocytic changes due to viral infection were not observed in all samples. Among EBV-positive cases (AM1, AM4, and AM6), there were two males and one female. All were located in the mandible with histological plexiform subtype. Two HPV positive cases (AM1 and AM7) consisted of one male and one female. Both of them were located in the mandible, with individual histological plexiform and follicular subtypes. After sequencing and blasting, both DNA matched to the HPV 18 (KU298886.1) completely. Our results found a noteworthy case (AM1) showing mixed EBV and HPV DNA (Fig. 1).

\section{Discussion}

The EBV and HPV are common cancer-associated viruses. Both viruses have permissive cells and induce tumorigenicity in specific cell types. ${ }^{14}$ Race is one of the dependent factors that affect frequencies of EBV and HPV DNA in each individual population. ${ }^{2}$ We have summarized the varied frequencies of EBV and HPV DNA in AM from acquired previous studies in Tables 3 and 4. Since, there is no data about the frequency of HPV and EBV DNA of AM in Thai population (PubMed Database, Scopus, and Web of Science), this preliminary study was carried out to evaluate both viruses' frequencies in Thai patients. Here, we found low frequencies of both viruses, which might suggest their minor involvement in a group of AM patients.

We observed $15 \%$ of EBV DNA in AM that was similar to the previous study by Fujita et al. ${ }^{19}$ and in range with other studies $\left(0,26.6\right.$, and $48 \%$ by Khalele et al., ${ }^{21}$ Badrawy et al., ${ }^{11}$ and Jang et al., ${ }^{20}$ respectively) (Table 3 ). The differences of frequency may be affected by the EBV detection technique and racial involvement. In general, the gold standard technique for EBV detection is by in situ hybridization (ISH) of EBER; however, the cost of this technique is very expensive. The PCR is more convenient and highly sensitive, but it might cause false-positive results that require confirmation by immunohistochemistry (IHC) using EBV antibodies or ISH EBVEBER. ${ }^{20}$ To ensure the results of this study, future investigations by the other techniques may be needed.

The EBV-associated Burkitt's lymphoma has a high prevalence in sub-Sahara area of Africa, whereas EBV-associated nasopharyngeal cancer has a high prevalence in South China area, ${ }^{20}$ suggesting that the incidence of EBV-associated cancer may be attributed to racial and/or geographic distribution. The current study in Thai AM patients showed the same frequency as that in Japanese AM patients ${ }^{19}$ but, however, was lower than that in Korean AM patients ${ }^{20}$ (Table 3).Due to the small sample size in our study, investigation of EBV and HPV DNA of AM in a larger population may increase the strength of this epidemiology. It is worth noting that two studies in Egypt showed unequal results that may be caused by different detection techniques. ${ }^{11,21}$

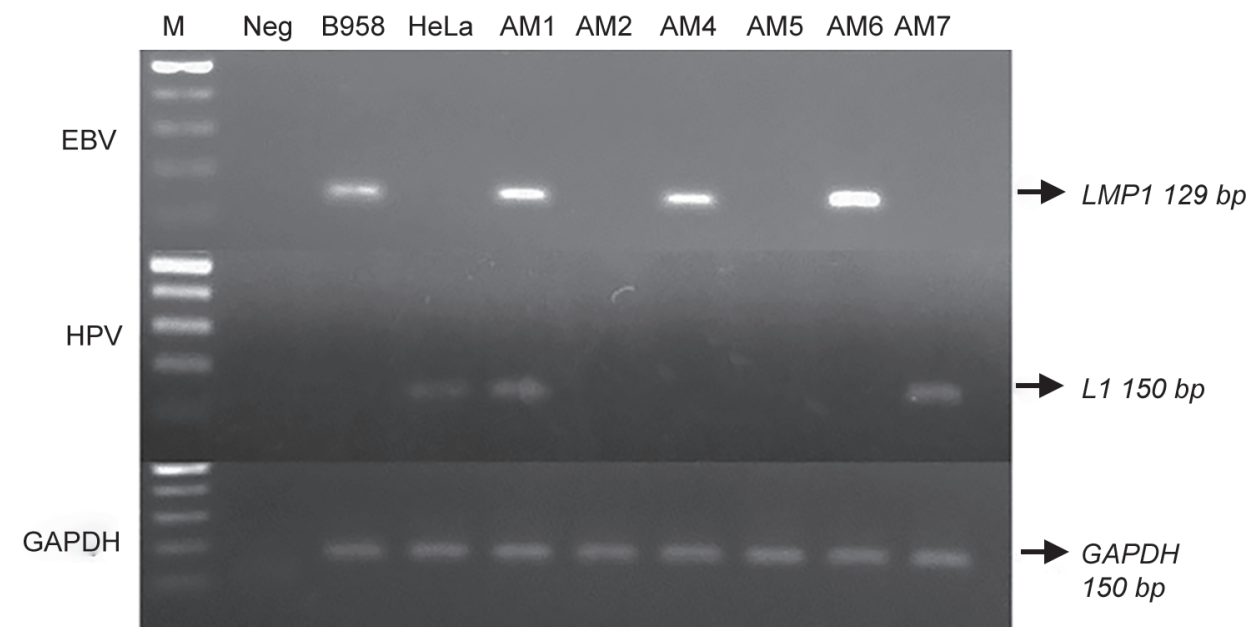

Fig. 1: Gel electrophoresis of EBV (LMP1) and HPV (L1) and GAPDH PCR in AM. Neg; distilled water used as negative control. B958 and HeLa cell lines DNA were used as positive controls. AM1, AM4, and AM6 showed positive for EBV PCR while AM1 and AM7 showed positive for HPV PCR. M: The ladder (left lane) is $100 \mathrm{bp}$ marker

Table 3: Review of EBV DNA frequency in ameloblastoma

\begin{tabular}{llllll}
\hline Study & Number of samples & EBV DNA $(\%, n)$ & Technique & Targeted gene & Country \\
\hline Fujita et al. ${ }^{19}$ & 53 & $15 \%(8 / 53)$ & In situ hybridization & EBER & Japan \\
Jang et al. $^{20}$ & 17 & $48 \%(8 / 17)$ & PCR & BamC, BMRF1, IR3 & Korea \\
Badrawy et al. $^{11}$ & 15 & $26.6 \%(4 / 15)$ & Real-time PCR & EBV genome & Egypt \\
Khalele $^{21}$ & 40 & $0 \%(0 / 40)$ & Immunohistochemistry & LMP1 & Egypt \\
This study & 20 & $15 \%(3 / 20)$ & PCR & LMP1 & Thailand \\
\hline
\end{tabular}

PCR; polymerase chain reaction 


\begin{tabular}{|c|c|c|c|c|c|}
\hline Study & Number of samples & $\operatorname{HPV} D N A(\%, n)$ & HPV typing & Technique & Country \\
\hline Kahn ${ }^{4}$ & 10 & $30 \%(3 / 10)$ & None reported & $\mathrm{IHC}$ & USA \\
\hline $\mathrm{Kahn}^{22}$ & 1 & $100 \%(1 / 1)$ & $16 / 18$ & $\mathrm{ISH}$ & USA \\
\hline van Heerden et al. ${ }^{23}$ & 1 & $100 \%(1 / 1)$ & 18 & $\mathrm{ISH}$ & South Africa \\
\hline Sand et al. ${ }^{24}$ & 18 & $27.8 \%(5 / 18)^{*}$ & $\begin{array}{l}1 \text { case; type } 18,3 \text { cases; mix } \\
18,6 / 11,1 \text { case; nonspecific }\end{array}$ & PCR & Sweden \\
\hline Namin et al. ${ }^{25}$ & 50 & $40 \%(20 / 50)$ & $\begin{array}{l}8 / 20 \text {; type } 6, \text { No types } 8,11 \\
16,18,31 \text {, or } 33\end{array}$ & PCR & Iran \\
\hline Migaldi et al. ${ }^{26}$ & 18 & $11 \%(2 / 18)$ & $\begin{array}{l}\text { Unknown, absence of type } 6 \\
11,16,18,31,33,35,52,58\end{array}$ & $\mathrm{IHC}, \mathrm{ISH}$, nested-PCR & Italy \\
\hline Mokhtari-Azad et al. ${ }^{27}$ & 100 & $32 \%(32 / 100)$ & $6,11,16,31$ & PCR & Iran \\
\hline Correnti et al. ${ }^{5}$ & 18 & $33.3 \%(6 / 18)$ & $\begin{array}{l}4 \text { cases; type } 6,1 \text { case; mix } \\
13,33 \text { and } 1 \text { case; mix 4,42 }\end{array}$ & $\begin{array}{l}\text { IHC, ISH, nested-PCR, IN- } \\
\text { NOLiPAHPV Genotyping } 2^{\circledast}\end{array}$ & Venezuela \\
\hline Badrawy et al. ${ }^{11}$ & 15 & $26.6 \%(4 / 15)$ & None reported & RT-PCR & Egypt \\
\hline Verduin et al. ${ }^{28}$ & 29 & $3.45 \%(1 / 29)$ & Low risk (6 or 11) & $\mathrm{ISH}$ & USA \\
\hline Singh et al. ${ }^{29}$ & 41 & $0 \%(0 / 41)$ & Not done & IHC, PCR & Australia \\
\hline Khalele ${ }^{21}$ & 40 & $0 \%(0 / 40)$ & Not done & $\mathrm{IHC}$ & Egypt \\
\hline $\begin{array}{l}\text { Zare Mahmoud Abadi } \\
\text { et al. } .^{30}\end{array}$ & 77 & $6.5 \%(5 / 77)$ & Not done & Real-time PCR & Iran \\
\hline This study & 20 & $10 \%(2 / 20)$ & 18 in both cases & PCR & Thailand \\
\hline
\end{tabular}

$\mathrm{ISH}$, in situ hybridization; IHC, immunohistochemistry; $\mathrm{PCR}$, polymerase chain reaction

*Primary surgery site

Another key oncogenic virus is HPV. Since 1989, more than 10 studies have reported the frequency of HPV DNA in AM that varied from 0 to $40 \%$ as summarized in Table 4. Our exploration is the first study in Southeast Asia and the HPV DNA frequency is 10\% that was similar to the report of Migaldi et al. ${ }^{26}$ Considering for HPV typing in Table 4, several studies encountered high-risk HPV and HPV 18 were mostly observed. ${ }^{22-25}$ Nevertheless, some studies displayed low-risk and intermediate-risk HPV types whichever may not involve in AM oncogenesis. In the present study, it is to be noted that both positive cases were HPV 18, the hrHPV that may be directly involved in AM oncogenesis.

Both HPV and EBV DNA have been remarkably observed in one case of $A M$. Regarding to the recent study reviewed the evidence of EBV and HPV co-infection in several cancers including cancer of nasopharynx, cervix, breast and prostate gland. ${ }^{31}$ Apolipoprotein B mRNA editing enzyme catalytic polypeptide3 (APOBEC3) deaminase was proven to involve virus innate immunity response and may promote viral coinfection. ${ }^{32}$ $A P O B E C 3 B$ mRNA levels were higher in oral squamous cell carcinoma compared to normal oral epithelium, ${ }^{33}$ but there is no study on $A P O B E C 3 B$ in AM. The study of APOBEC 3 in this case may elucidate whether the coinfection of EBV and HPV plays any role in the development of AM.

The EBV and HPV association in AM oncogenesis has been curiously underlined. In this study, we did not observe koilocytic changes in both HPV positive samples, meaning that no morphological appearance of HPV infection like what observed in the study of Migaldi et al. ${ }^{26}$ We also did not observe syncytial formation in EBV-positive cases. Both viruses may transform normal odontogenic epithelium to ameloblastoma epithelial cells without any feature of viral cytopathologic changes. It was also suggested that HPV in AM may represent a background infection without AM oncogenesis development. ${ }^{28}$
Sensitivity of PCR technique should also be a concern. Both HPV and EBV DNA might contaminate in normal epithelium or from the surgically acquired contamination during the procedure. In the other aspects, the common permissive cells of EBV are lymphocytes and epithelial cells, while of HPV are epithelial cells. ${ }^{8,31,34}$ Several reports exhibited HPV and EBV positive cases derived from the in situ hybridization technique and demonstrated EBV and HPV infected in AM cells. ${ }^{5,19,22,23,26,28}$ (Tables 3 and 4). We hypothesize that AM may possess EBV and HPV receptors, which need to be explored in further studies. To evaluate if EBV and HPV were related to $A M$ oncogenesis, the PCR positive cases must be confirmed by ISH or IHC.

\section{Conclusion}

The low frequencies of EBV and HPV DNA in a group of Thai AM patients may suggest their minor participation in the biological events related to AM pathogenesis. Nevertheless, it could not be concluded that the virus was involved in the etiology and pathogenesis of the lesions. These studies are preliminary in nature involving limited number of AM patients and hence further work with a larger sample size comprising various techniques is required. Finally, the studies of in-depth mechanisms in the role of viruses in $\mathrm{AM}$ oncogenesis were suggested for further prevention and treatment of virus-associated ameloblastoma.

\section{Clinical Significance}

HPV and EBV may not be involved in ameloblastogenesis.

\section{Availability of Data and Materials}

The data analyzed during this present study are available from corresponding author on reasonable request. 


\section{Author's Contributions}

Dusit Bumalee and Nakarin Kitkumthorn conceived the original idea, designed the experiment, analyzed data, and interpreted results. Dusit Bumalee, Puangwan Lapthanasupkul, Eakapong Tamboon, Anchisa Aittiwarapoj, Boworn Klongnoi, and Nakarin Kitkumthorn performed the experiment and collected data. Dusit Bumalee wrote the manuscript with support from Nakarin Kitkumthorn. All authors read and approved the final manuscript.

\section{Ethics Approval and Consent to Participate}

This study was approved by the Institutional Review Board of Faculty of the Dentistry/Faculty of Pharmacy, Mahidol University, Bangkok, Thailand (approval number: 2018/005.1101).

\section{Consent to Publish}

The authors have given the consent for publication.

\section{References}

1. Yanatatsaneejit $P$, Boonsuwan $T$, Mutirangura $A$, et al. XRCC1 gene polymorphisms and risk of ameloblastoma. Archs Oral Biol 2013;58(6):583-589. DOI: 10.1016/j.archoralbio.2012.10.016.

2. Worawongvasu R, Tiensuwan M. Odontogenic tumors in Thailand: a study of 590 Thai patients. J Oral Maxillofac Surg Med Pathol 2015;27(4):567-576. DOI: 10.1016/j.ajoms.2014.11.004.

3. Effiom O, Ogundana O, Akinshipo A, et al. Ameloblastoma: current etiopathological concepts and management. Oral Dis 2018;24(3):307316. DOI: 10.1111/odi.12646.

4. Kahn MA. Ameloblastoma in young persons: a clinicopathologic analysis and etiologic investigation. Oral Surg Oral Med Oral Pathol 1989;67(6):706-715. DOI: 10.1016/0030-4220(89)90013-3.

5. Correnti M, Rossi M, Avila M, et al. Human papillomavirus in ameloblastoma. Oral Surg Oral Med Oral Pathol Oral Radiol Endod 2010;110(3):e20-e24. DOI: 10.1016/j.tripleo.2010.04.030.

6. Niedobitek G, Meru N, Delecluse HJ. Epstein-Barr virus infection and human malignancies. Int J Exp Pathol 2001;82(3):149-170. DOI: 10.1111/j.1365-2613.2001.iep190.x.

7. zur Hausen H. Papillomaviruses in the causation of human cancers-a brief historical account. Virology 2009;384(2):260-265. DOI: 10.1016/j. virol.2008.11.046.

8. Pandhi D, Sonthalia S. Human papilloma virus vaccines: current scenario. Indian J Sex Transm Dis AIDS 2011;32:75-85.

9. Bhattarakosol P, Lertworapreecha M, Kitkumthorn N, et al. Survey of human papillomavirus infection in cervical intraepithelial neoplasia in Thai women. J Med Assoc Thai 2002;85:S360-S365.

10. Kitkumthorn N, Yanatatsanajit P, Kiatpongsan S, et al. Cyclin A1 promoter hypermethylation in human papillomavirus-associated cervical cancer. BMC Cancer 2006;6(1):55. DOI: 10.1186/1471-2407-655.

11. Badrawy $H, A b d$-Elmagid $A$, Hosam $M$, et al. Detection of EBV and $\mathrm{HPV}$ in oral squamous cell carcinoma and ameloblastoma: real time polymerase chain reaction study. JCTI 2014;1(1):7-18. DOI: 10.9734/ JCTI/2014/15874.

12. Shannon-Lowe C, Rickinson A.The global landscape of EBV-associated tumours. Front Oncol 2019;9:713. DOI: 10.3389/fonc.2019.00713.

13. Yanatatsaneejit $P$, Mutirangura A, Kitkumthorn N. Human papillomavirus's physical state and cyclin A1 promoter methylation in cervical cancer. Int J Gynecol Cancer 2011;21(5):902-906. DOI: 10.1097/IGC.0b013e3182158683.

14. Morales-Sánchez A, Fuentes-Pananá E. Human viruses and cancer. Viruses 2014;6(10):4047-4079. DOI: 10.3390/v6104047.

15. El-Naggar A, Chan J, Takata T, et al. WHO classification of tumours. Pathology and genetics of head and neck tumours. Lyon: IARC Press; 2017.
16. SambrookJ, Russell DW. Purification of nucleic acids by extraction with phenol: chloroform. Cold Spring Harbor Protocols 2006;2006(1):pdb. prot4455.

17. de Roda Husman A-M, Walboomers JMM, van den Brule AJC, et al. The use of general primers GP5 and GP6 elongated at their 3' ends with adjacent highly conserved sequences improves human papillomavirus detection by PCR. J Gen Virol 1995;76(4):1057-1062. DOI: 10.1099/0022-1317-76-4-1057.

18. Wanvimonsuk S, Thitiwanichpiwong P, Keelawat S, et al. Distribution of the Epstein-Barr virus in the normal stomach and gastric lesions in Thai population. J Med Virol 2019;91(3):444-449. DOI: 10.1002/ jmv.25318.

19. Fujita $\mathrm{S}$, Shibata $\mathrm{Y}$, Takahashi $\mathrm{H}$, et al. Latent infection with Epstein-Barr virus in odontogenic disorders: comparison among ameloblastoma, dentigerous cyst and odontogenic keratocyst. Pathol Int 1997;47(7):449-453. DOI: 10.1111/j.1440-1827.1997. tb04523.x.

20. Jang HS, Cho JO, Yoon CY, et al. Demonstration of Epstein-Barr virus in odontogenic and nonodontogenic tumors by the polymerase chain reaction (PCR). J Oral Pathol Med 2001;30(10):603-610. DOI: 10.1034/j.1600-0714.2001.301005.x.

21. Khalele BA. The anecdote of viral etiopathogenia in ameloblastoma and odontogenic keratocyst: why don't we let it go? J Oral Bio Craniofac Res 2017;7(2):101-105. DOI: 10.1016/j.jobcr.2017.04.002.

22. Kahn MA. Demonstration of human papillomavirus DNA in a peripheral ameloblastoma by in situ hybridization. Hum Pathol 1992;23(2):188-191. DOI: 10.1016/0046-8177(92)90242-U.

23. Heerden WFP, Rensburg EJ, Raubenheimer EJ, et al. Detection of human papillomavirus DNA in an ameloblastoma using the in situ hybridization technique. J Oral Pathol Med 1993;22(3):109-112. DOI: 10.1111/j.1600-0714.1993.tb01039.x.

24. Sand L, Jalouli J, Larsson P-A, et al. Presence of human papilloma viruses in intraosseous ameloblastoma. J Oral Maxillofac Surg 2000;58(10):1129-1134. DOI: 10.1053/joms.2000.9573.

25. Namin AK, Azad TM, Eslami B, et al. A study of the relationship between ameloblastoma and human papilloma virus. J Oral Maxillofac Surg 2003;61(4):467-470. DOI: 10.1053/joms.2003. 50011.

26. Migaldi M, Pecorari M, Rossi G, et al. Does HPV play a role in the etiopathogenesis of ameloblastoma? an immunohistochemical, in situ hybridization and polymerase chain reaction study of 18 cases using laser capture microdissection. Mod Pathol 2005;18(2):283. DOI: 10.1038/modpathol.3800241.

27. Mokhtari-Azad T, Moradi A, Khodayari-Nemin A, et al. Detection of human papillomavirus DNA in intraosseus ameloblastoma. Intl J Virol 2006;2(1):1-6. DOI: 10.3923/ijv.2006.1.6.

28. Verduin L, Bishop J, Mills SE. Gnathic and peripheral ameloblastomas lack human papillomavirus DNA. Ann Diagn Pathol 2015;19(5):306309. DOI: 10.1016/j.anndiagpath.2015.06.006.

29. Singh T, Angel C, Tabrizi $S$, et al. Ameloblastoma, human papillomavirus, and p16-is there an association. Arch Otolaryngol Rhinol 2016;2:20-24. DOI: 10.17352/2455-1759.000016.

30. Zare Mahmoud Abadi R, Saghafi S, Mohajertehran F, et al. Detection of human papillomavirus (HPV) in ameloblastoma using the polymerase chain reaction (PCR). J Mash Dent Sch 2019;42:298-306.

31. Shi $Y$, Peng $S-L$, Yang $L-F$, et al. Co-infection of Epstein-Barr virus and human papillomavirus in human tumorigenesis. Chin J Cancer 2016;35(1):16. DOI: 10.1186/s40880-016-0079-1.

32. Stavrou S, Ross SR. APOBEC3 proteins in viral immunity. J Immunol 2015;195(10):4565-4570. DOI: 10.4049/jimmunol.1501504.

33. Fanourakis G, Tosios K, Papanikolaou N, et al. Evidence for APOBEC3B mRNA and protein expression in oral squamous cell carcinomas. Exp Mol Pathol 2016;101(3):314-319. DOI: 10.1016/j.yexmp.2016. 11.001.

34. Kikuchi $\mathrm{K}$, Inoue $\mathrm{H}$, Miyazaki $\mathrm{Y}$, et al. Epstein-Barr virus (EBV)associated epithelial and non-epithelial lesions of the oral cavity. Jpn Dent Sci Rev 2017;53(3):95-109. DOI: 10.1016/j.jdsr.2017. 01.002 . 